\title{
Potential biomarkers of DNA replication stress in cancer
}

\author{
Liqun Ren ${ }^{1}$, Long Chen ${ }^{1}$, Wei Wu², Lorenza Garribba ${ }^{2}$, Huanna Tian ${ }^{1}$, Zihui Liu ${ }^{3}$, \\ Ivan Vogel ${ }^{2}$, Chunhui Li ${ }^{3}$, Ian D. Hickson ${ }^{2,4}$ and Ying Liu ${ }^{2}$ \\ ${ }^{1}$ Basic Medical Research Institute, Chengde Medical University, Chengde, China \\ ${ }^{2}$ Center for Chromosome Stability, Department of Cellular and Molecular Medicine, University of Copenhagen, Copenhagen, \\ Denmark \\ ${ }^{3}$ Pathology Department, Affiliated Hospital, Chengde Medical University, Chengde, China \\ ${ }^{4}$ Center for Healthy Aging, Department of Cellular and Molecular Medicine, University of Copenhagen, Copenhagen, Denmark \\ Correspondence to: Ying Liu, email: ying@sund.ku.dk \\ Keywords: cancer biomarker, chromosome instability, common fragile sites, MiDAS, replication stress, Chromosome Section \\ Received: March 08, $2017 \quad$ Accepted: March 28, $2017 \quad$ Published: April 07, 2017
}

Copyright: Ren et al. This is an open-access article distributed under the terms of the Creative Commons Attribution License (CC-BY), which permits unrestricted use, distribution, and reproduction in any medium, provided the original author and source are credited.

\section{ABSTRACT}

Oncogene activation is an established driver of tumorigenesis. An apparently inevitable consequence of oncogene activation is the generation of DNA replication stress (RS), a feature common to most cancer cells. RS, in turn, is a causal factor in the development of chromosome instability (CIN), a near universal feature of solid tumors. It is likely that CIN and RS are mutually reinforcing drivers that not only accelerate tumorigenesis, but also permit cancer cells to adapt to diverse and hostile environments. This article reviews the genetic changes present in cancer cells that influence oncogene-induced RS and CIN, with a particular emphasis on regions of the human genome that show enhanced sensitivity to the destabilizing effects of RS, such as common fragile sites. Because RS exists in a wide range of cancer types, we propose that the proteins involved counteracting this stress are potential biomarkers for indicating the degree of RS in cancer specimens. To test this hypothesis, we conducted a pilot study to validate whether some of proteins that are known from in vitro studies to play an essential role in the RS pathway could be suitable as a biomarker. Our results indicated that this is possible. With this review and pilot study, we aim to accelerate the development of a biomarker for analysis of RS in tumor biopsy specimens, which could ultimately help to stratify patients for different forms of therapy such as the RS inhibitors already undergoing clinical trials.

\section{INTRODUCTION}

Despite huge advances in our understanding of basic cancer biology, the incidence of cancer worldwide is still rising, and the overall survival rates for patients with advanced cancer are still low. For example, a World Health Organization report in 2012 revealed that there were approximately 14 million newly recorded cases of cancer worldwide that year, as well as over 8 million cancer-related deaths [1]. Four years on from this report, the same general picture remains, with a particularly negative outlook existing for advanced cancers. Taking colon cancer cases recorded during 2014-2015 in the USA as an example, those patients with early stage disease (Stage I) had a greater than $90 \%$ chance of surviving for more than 5 years after diagnosis. Unfortunately, however, only around $40 \%$ of cases are diagnosed at such an early disease stage. In those cases where the cancer had spread to distant organs (stage IV patient), the 5-year survival dropped dramatically to only around $15 \%$. The five-year survival rate for all colon cancer is currently around $65 \%$ [2]. Clearly, to significantly improve the survival of cancer patients, progress must be made in targeting those cancers that are at an advanced stage at the point of diagnosis.

Cancer cells differ from most normal cells in that they display an unlimited capacity for proliferation. This altered proliferative capacity is a consequence of the effects of genetic changes that arise during tumorigenesis, which are generally acquired as part of a sequential, multi-step process. Somewhat ironically, the 
same mutation-selection evolutionary law that Darwin described for the development of different species shapes this pathological 'evolutionary' process. In the case of cancer development, the mutations are either inherited, or more frequently acquired somatically. Recent cancer genome sequencing efforts have revealed a bewildering array of different mutations in many of the most common cancers. Nevertheless, in many cases, there appears to be a common set of genes mutated characteristically in a particular tumor type. Cells carrying these genetic changes are then subjected to powerful selection imposed by the environment in which the cell resides. As a result, cancers often 'evolve' differently in different organs and even in the same organ from different patients. Moreover, their ability to invade surrounding tissue, as well as to spread to and survive within distant organs, can be very different. This genetic and phenotypic diversity has imposed huge challenges for the development of curative therapies because 'one size clearly does not fit all' when it comes to selection of the appropriate treatment options.

It is well established that cancers arise primarily as a result of a series of changes to two classes of genes: oncogenes and tumor suppressor genes. These changes result either in the activation of the oncogene or in the inactivation of the tumor suppressor gene, and are often termed 'driver mutations'. For example, approximately 15 different driver mutations (as well as $>60$ 'passenger' mutations that are not directly involved in tumorigenesis) have been found in colon cancers [3]. When oncogenes become activated, one of the main consequences is the development of so-called 'DNA replication stress' (RS). While RS lacks a clear universal definition, it is usually taken to mean a situation in which DNA replication forks are disrupted leading to DNA damage and/or the accumulation of single stranded DNA. This leads to a DNA damage checkpoint response associated with the activation of the ATR and CHK1 kinases. If this disruption to replication is not dealt with promptly or appropriately, RS can lead to detrimental consequences including chromosome translocations or whole chromosome missegregation during mitosis leading to aneuploidy. Although initially considered a rare event associated only with a limited set of oncogenes, recent research has revealed that $\mathrm{RS}$ is triggered by the activation of a wide range of oncogenes, including many of the most common cancer-associated events such as c-Myc amplification, mutation of Ras, and overexpression of Cyclin D or the replication licensing factors Cdt1 and Cdc6 [4, 5].

There is a large body of evidence to indicate that chromosomal instability (CIN) in cancer cells is a driving force during tumorigenesis, and one of the major causes not only of heterogeneity in cancer cells, but also of cancer cell resistance to radiotherapy and chemotherapy [6]. As alluded to above, it has been proposed that RS plays a central role in the generation of structural and numerical CIN [7]. Indeed, it is conceivable that CIN and RS are mutually reinforcing drivers that permit cancer cells to have a selective advantage when adapting to a challenging environments. This raises the question of whether we can define a common molecular pathway or process that exists in many, if not all, cancers, that would allow us to identify a useful cancer biomarker? This article will focus on the genetic changes present in cancer cells that influence oncogene-induced RS and CIN, with a particular emphasis on common fragile sites (CFSs) in the human genome because of an accumulating body of evidence indicating that these loci are major hotspots for cancerassociated genome rearrangements due to their exquisite sensitivity to RS. We will also present pilot data pertaining to the identification of potential markers of RS in cancer biopsies. Ultimately, such a marker would help to stratify patients on the basis of whether they might be particularly vulnerable to the acquisition of advanced-stage and/or therapy-resistant disease.

\section{RESULTS}

\section{Chromosomal changes in cancer cells}

More than 100 years ago, Theodor Boveri speculated on the role of chromosome instability in cancer, based on his work in sea urchins. He reasoned that 'a cancerous tumor begins with a single cell in which the makeup of its chromosomes becomes scrambled, causing the cells to divide uncontrollably' [8]. It is now well established that cancer cells display two distinct types of karyotypic abnormalities. The first is a change in chromosome number (aneuploidy), and the second is a change in the structure of individual chromosomes caused by exchanges or rearrangements. These changes can be observed using conventional karyotyping (Figure 1), but are more evident when using a more advanced method such as spectral karyotyping (SKY), which employs fluorescentlylabeled probes to mark all of the DNA originating from a particular chromosome. It is known that about $85 \%$ of solid tumors show CIN in the form of aneuploidy, which is also the underlying cause of copy number changes of proto-oncogenes [9]. Indeed, we now know that many of the structural changes in individual chromosomes are directly responsible for the activation of oncogenes (via translocation or duplication) or inactivation of tumor suppressor genes (via deletion or mutation).

\section{Chromosome number changes}

The chromosome number changes that are characteristic of cancers are frequently caused by the inaccurate segregation of chromosomes during mitosis. To ensure that an equal number of chromosomes are distributed to the two daughter cells, progression through 
the key stages of mitosis is monitored by a series of checkpoints involving over 100 proteins. Thus far, four major changes have been described that can lead to the onset of chromosome number changes in tumors. The first is a defect in the spindle assembly checkpoint (SAC) caused by mutation or deregulation of any of several proteins, including $B U B 1 B, M A D 1 L 1, M A D 2 L 1$, and CENPE [10-12]. The second cause is a defect in microtubule attachment, with perhaps the most destructive form being so-called 'merotely', where one kinetochore becomes attached to microtubules from opposite spindle poles. Kinetochores are often observed to be merotelically attached to spindles in the early stages of mitosis, but this is generally corrected during metaphase [13, 14]. However, when aberrantly attached kinetochores persist until anaphase, sister chromatid missegregation usually results. The control of kinetochore-microtubule attachment is governed by an extensive network of different proteins, including PLK1, the Aurora A and B kinases, and cyclin-CDK complexes, which have been reported dysregulated in cancer cells (reviewed in [15]). A third cause for chromosome number changes is the existence of supernumerary centrosomes in mitotic cells, which can result either directly through a failure to suppress centriole over-duplication [16] or indirectly because of an aborted mitosis due to cytokinesis failure. The fourth major cause is via defects in the cohesin protein complex that holds sister chromatids together after DNA replication until anaphase. For example, loss of function mutations in STAG2, which encodes the cohesin protein complex subunit SA-2, has been found in cancer cell lines and in primary tumors [17]. Indeed, CIN can be induced in a karyotypically stable cell line following transfection of a mutated STAG2 cDNA [17]. Similarly, some CIN cell lines have defects in the recruitment of Shugoshin 1 protein (SGO1) that coordinates sister chromatid cohesion and kinetochore-microtubule attachment [18].

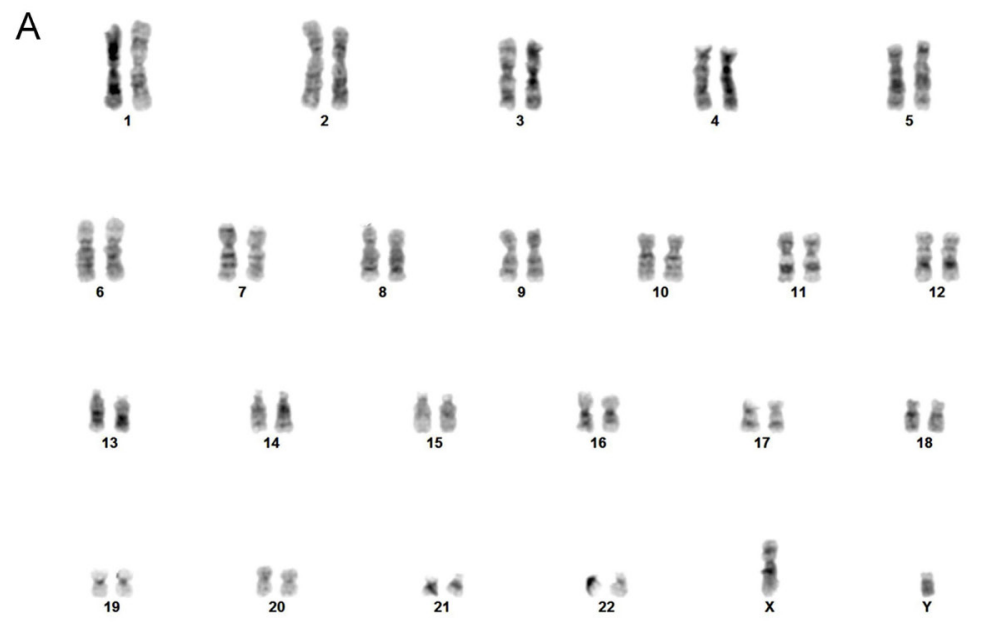

B

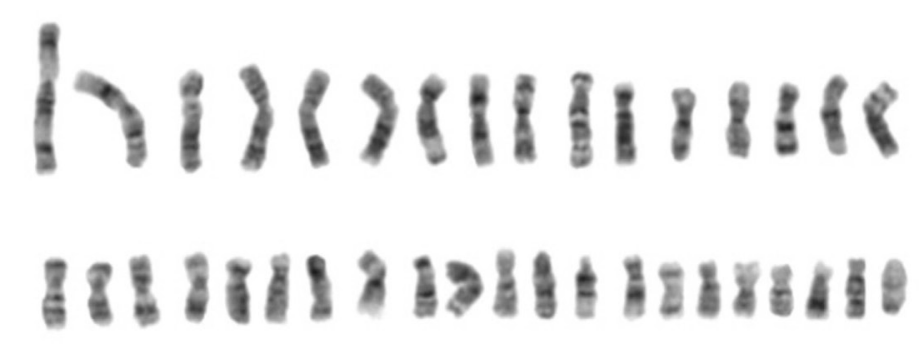

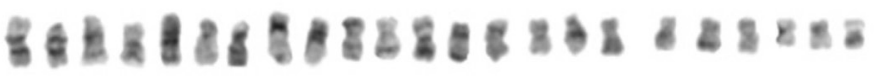

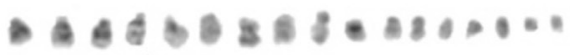

Figure 1: Representative karyotypes of a virally transformed lymphocyte from a normal individual (GM06865) (A), and of an osteosarcoma cell line (U2OS) with CIN (B). Unlike the diploid normal lymphocyte, the aneuploidy U2OS cell karyotype is highly abnormal with many chromosomes showing such an abnormal G-banding pattern that they could not be reliably assigned. 


\section{Chromosome structural changes}

Recent cancer genome sequencing efforts have revealed that a set of unstable regions of the genome called common fragile sites (CFSs) lead to recurrent chromosomal structural changes in cancers. This assertion is based on three observations: (i) Some oncogenes or tumor suppressor genes are encoded within CFS loci [19]; (ii) CFS sequences are frequently found at the breakpoints of cancer-specific DNA translocations [2024], and (iii) A significant proportion of the regions most frequently associated with focal deletions in cancer lie in CFS loci [25]. CFSs are chromosomal loci that tend to form a gap, break or constriction that is visible on condensed metaphase chromosomes. Despite their inherent instability, CFSs are evolutionally conserved chromosomal regions and, for example, generally map to syntenic regions of mouse and human chromosomes [26]. Moreover, they are present in all individuals. Their

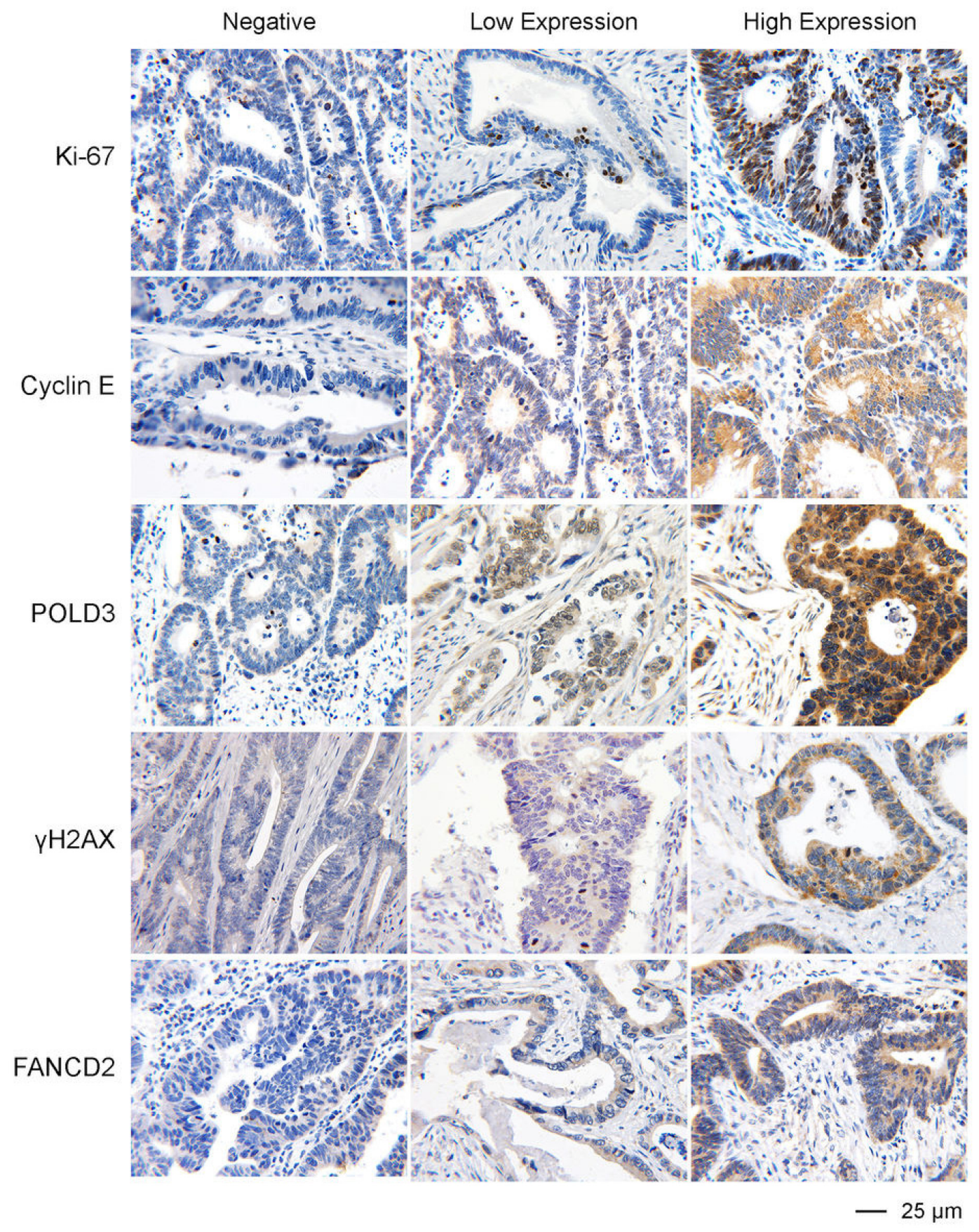

Figure 2: Representative IHC images of the expression of Ki-67, Cyclin E, POLD3, $\gamma \mathrm{H} 2 \mathrm{AX}$, and FANCD2 in colon cancer FFPE specimens. 
broken appearance (usually termed CFS 'expression') can be induced by exposing cells to agents that partially inhibit DNA synthesis, such as the DNA polymerase inhibitor aphidicolin (APH) [27]. To date, more than 200 CFSs have been identified in the human genome using this method [28].

Great advances have been made towards understanding the mechanism underlying CFS expression. The currently accepted model is that CFS expression reflects an inability to effect chromatin condensation due to a failure to complete DNA replication at the locus prior to mitotic entry $[29,30]$. This, of course, begs the question as to why completion of DNA replication would ever be impaired in some regions of the human genome. To address this question, several research groups have sought to define the molecular events leading to CFS expression following replication perturbation. One revealing feature of CFSs is that they recruit several DNA repair and DNA damage response proteins during conditions of RS, including ATR [31], BRCA1 [32], CHK1 [33], FANCD2 [34], RAD51, and $\gamma \mathrm{H} 2 \mathrm{AX}$ [35].

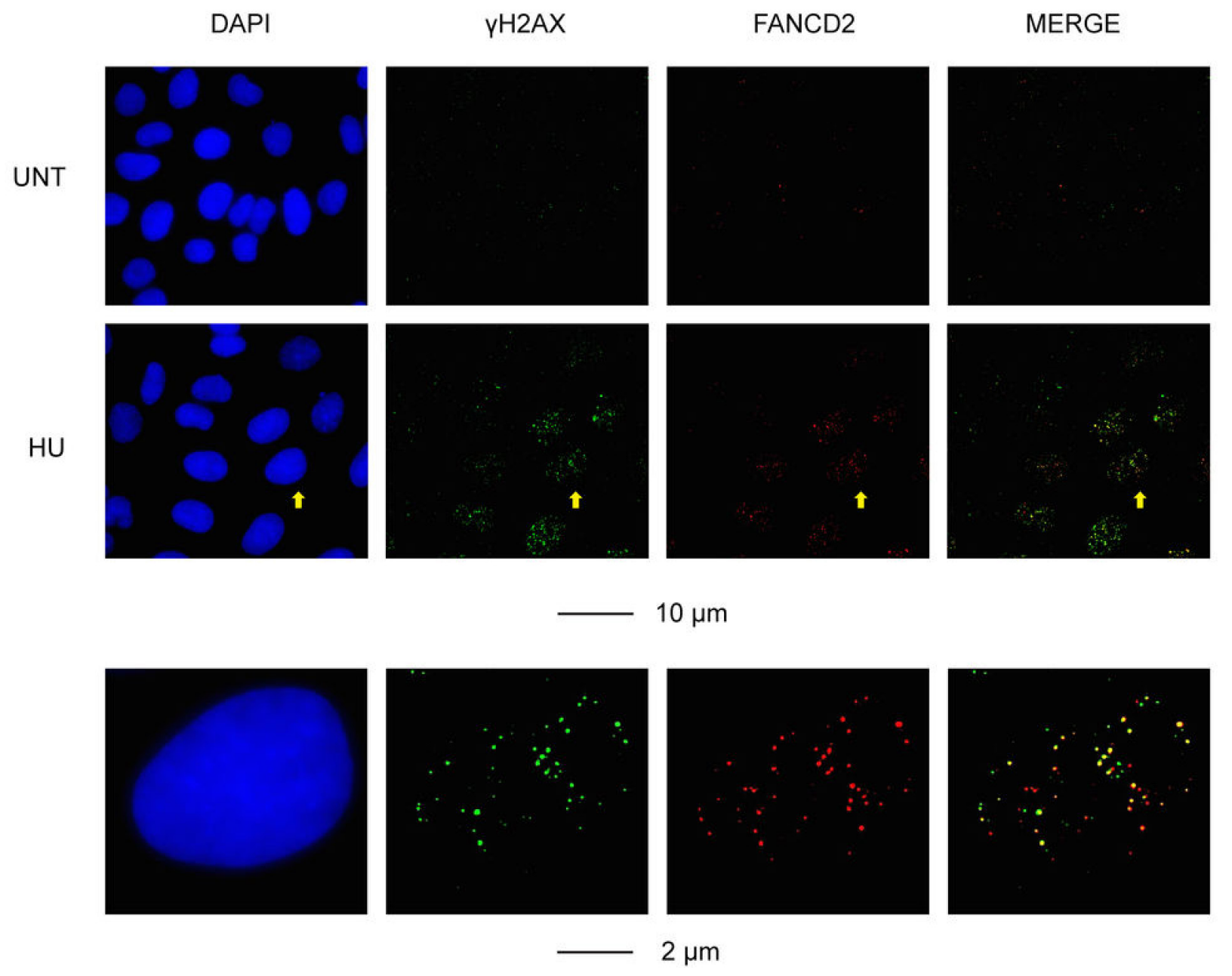

In our laboratory, we have focused on the FANCD2 protein, which serves as excellent surrogate marker of the location of CFSs undergoing RS, because it binds to CFS loci irrespective of whether the chromosome is broken or not in metaphase [36]. FANCD2 foci first associate with CFSs in late $\mathrm{S} / \mathrm{G} 2$ and remain there through mitosis, ultimately segregating evenly with the sister chromatids in anaphase. Indeed, it is clear that under-replicated CFSs recruit multiple DNA repair proteins, including the DNA structure-selective endonuclease MUS81-EME1 in early mitosis, and that this promotes CFS expression [37]. This discovery is consistent with the notion that the expression of CFSs is not an accidental event, but instead is a programmed and regulated process. Indeed, we have proposed that CFS expression is actually beneficial for the maintenance of genome stability, because it prevents much more hazardous events, such as irreversible chromosome missegregation [37].

It has also been demonstrated recently that FANCD2 plays a direct role in CFS replication through an ability to promote the resolution of DNA:RNA hybrids [38]. 
Table 1: A summary of the expression of Ki-67, Cyclin E, POLD3, $\gamma H 2 A X$, and FANCD2 in 32 FFPE specimens from colon, lung, breast, and stomach cancer patients by IHC analysis.

\begin{tabular}{|c|c|c|c|c|c|c|c|c|c|c|c|c|}
\hline $\begin{array}{c}\text { Case } \\
\text { Number }\end{array}$ & Sex & Age & Tumor location & $\begin{array}{c}\text { Macroscopic } \\
\text { type }\end{array}$ & Histologic type & $\begin{array}{c}\text { Degree of } \\
\text { differentiation }\end{array}$ & \begin{tabular}{|c|}
$\begin{array}{c}\text { Clinical } \\
\text { stage }\end{array}$ \\
\end{tabular} & Ki-67 & Cyclin E & POLD3 & $\gamma \mathrm{H} 2 \mathrm{AX}$ & FANCD2 \\
\hline 1 & $\mathrm{~F}$ & 50 & Colon, Right-side & Ulcerative type & adenocarcinoma & Moderate & IIA & ++ & ++ & ++ & - & ++ \\
\hline 2 & $\mathrm{~F}$ & 58 & Colon, Right-side & Ulcerative type & adenocarcinoma & Moderate & IIA & ++ & ++ & ++ & - & ++ \\
\hline 3 & $\mathrm{~F}$ & 68 & Colon, Right-side & Ulcerative type & adenocarcinoma & Moderate & IIA & - & ++ & ++ & ++ & ++ \\
\hline 4 & $\mathrm{~F}$ & 69 & Colon, Right-side & Ulcerative type & adenocarcinoma & Moderate & IIA & - & ++ & ++ & - & - \\
\hline 5 & M & 28 & $\begin{array}{c}\text { Colon, } \\
\text { Transverse+sigmoid }\end{array}$ & Ulcerative type & adenocarcinoma & Moderate & IIIB & + & ++ & ++ & - & ++ \\
\hline 6 & $\mathrm{M}$ & 50 & Colon, Rectum & Ulcerative type & adenocarcinoma & Moderate & IIA & + & ++ & ++ & + & ++ \\
\hline 7 & $\mathrm{~F}$ & 76 & Colon, Right-side & Ulcerative type & adenocarcinoma & Moderate & IIA & - & ++ & ++ & - & + \\
\hline 8 & $\bar{M}$ & 71 & Colon, Sigmoid colon & Ulcerative type & adenocarcinoma & Moderate & IIA & ++ & ++ & ++ & ++ & + \\
\hline 9 & $\mathrm{~F}$ & 76 & Colon,Right-side & Ulcerative type & adenocarcinoma & Moderate & IIA & + & ++ & ++ & + & ++ \\
\hline 10 & $\mathrm{~F}$ & 62 & Colon,Ileocecus & Ulcerative type & adenocarcinoma & Moderate & IIIC & ++ & ++ & ++ & + & - \\
\hline 11 & M & 51 & $\begin{array}{l}\text { Lung, superior lobe of } \\
\text { right lung }\end{array}$ & peripheral type & $\begin{array}{l}\text { squamous } \\
\text { carcinoma }\end{array}$ & Moderate & IA & ++ & + & ++ & + & + \\
\hline 12 & M & 66 & $\begin{array}{l}\text { Lung, superior lobe of } \\
\text { left lung }\end{array}$ & peripheral type & $\begin{array}{l}\text { squamous } \\
\text { carcinoma }\end{array}$ & Moderate & IB & ++ & ++ & + & - & + \\
\hline 13 & M & 51 & $\begin{array}{l}\text { Lung, superior lobe of } \\
\text { right lung }\end{array}$ & central type & $\begin{array}{l}\text { squamous } \\
\text { carcinoma }\end{array}$ & Moderate & IIIA & - & + & - & - & - \\
\hline 14 & M & 61 & $\begin{array}{c}\text { Lung, inferior lobe of } \\
\text { right lung }\end{array}$ & central type & $\begin{array}{l}\text { squamous } \\
\text { carcinoma }\end{array}$ & Moderate & IA & ++ & - & ++ & - & ++ \\
\hline 15 & M & 57 & $\begin{array}{l}\text { Lung, superior lobe of } \\
\text { left lung }\end{array}$ & peripheral type & $\begin{array}{c}\text { adenosquamous } \\
\text { carcinoma }\end{array}$ & Moderate & IB & - & + & ++ & + & - \\
\hline 16 & M & 68 & $\begin{array}{l}\text { Lung, superior lobe of } \\
\text { right lung }\end{array}$ & peripheral type & adenocarcinoma & Moderate & IA & - & - & + & + & - \\
\hline 17 & $\mathrm{~F}$ & 56 & Lung, right lung & peripheral type & adenocarcinoma & Moderate & IA & - & ++ & - & ++ & + \\
\hline 18 & M & 52 & $\begin{array}{l}\text { Lung, superior lobe of } \\
\text { left lung }\end{array}$ & central type & $\begin{array}{l}\text { squamous } \\
\text { carcinoma }\end{array}$ & Moderate-low & IIB & + & ++ & ++ & + & - \\
\hline 19 & $\mathrm{~F}$ & 57 & Breast, right side & l & $\begin{array}{l}\text { infiltrating } \\
\text { lobular } \\
\text { carcinoma }\end{array}$ & Moderate & IA & - & + & ++ & - & - \\
\hline 20 & $\mathrm{~F}$ & 45 & Breast, left side & l & $\begin{array}{c}\text { infiltrating ductal } \\
\text { carcinoma }\end{array}$ & Moderate & IIA & - & ++ & ++ & + & - \\
\hline 21 & $\mathrm{~F}$ & 46 & Breast, left side & l & \begin{tabular}{|c|}
$\begin{array}{c}\text { infiltrating ductal } \\
\text { carcinoma }\end{array}$ \\
\end{tabular} & Moderate & IIA & - & + & ++ & - & - \\
\hline 22 & $\mathrm{~F}$ & 50 & Breast, right side & l & \begin{tabular}{|c|}
$\begin{array}{c}\text { infiltrating ductal } \\
\text { carcinoma }\end{array}$ \\
\end{tabular} & Moderate & IA & - & + & ++ & - & - \\
\hline 23 & $\mathrm{~F}$ & 56 & Breast, left side & / & $\begin{array}{c}\begin{array}{c}\text { infiltrating ductal } \\
\text { carcinoma }\end{array} \\
\end{array}$ & Moderate & IIA & - & + & + & - & ++ \\
\hline 24 & $\mathrm{~F}$ & 47 & Breast, right side & / & $\begin{array}{l}\text { introductal } \\
\text { carcinoma }\end{array}$ & Moderate & 0 & - & + & ++ & - & + \\
\hline 25 & $\mathrm{~F}$ & 60 & Breast, left side & / & $\begin{array}{c}\begin{array}{c}\text { infiltrating ductal } \\
\text { carcinoma }\end{array} \\
\end{array}$ & Moderate & IA & - & + & ++ & - & - \\
\hline 26 & $\mathrm{~F}$ & 51 & Breast, left side & l & $\begin{array}{c}\text { infiltrating ductal } \\
\text { carcinoma }\end{array}$ & Moderate & IIA & - & + & + & - & - \\
\hline 27 & $\mathrm{~F}$ & 36 & Breast, right side & / & $\begin{array}{c}\begin{array}{c}\text { infiltrating ductal } \\
\text { carcinoma }\end{array} \\
\end{array}$ & Moderate & IIIA & ++ & - & ++ & - & + \\
\hline 28 & $\mathrm{~F}$ & 56 & $\begin{array}{l}\text { Stomach, Ulcerative } \\
\text { type }\end{array}$ & Ulcerative type & adenocarcinoma & Moderate & IIA & - & ++ & ++ & - & - \\
\hline 29 & $\mathrm{M}$ & 47 & Stomach & Ulcerative type & adenocarcinoma & Moderate & IB & - & + & ++ & + & + \\
\hline 30 & $\mathrm{~F}$ & 42 & Stomach & Ulcerative type & adenocarcinoma & Moderate & IIA & - & + & ++ & + & ++ \\
\hline 31 & $\mathrm{~F}$ & 67 & Stomach & Ulcerative type & adenocarcinoma & Moderate & IB & - & ++ & ++ & - & + \\
\hline 32 & $\mathrm{M}$ & 63 & Stomach & Ulcerative type & adenocarcinoma & Moderate & IB & - & ++ & ++ & + & ++ \\
\hline
\end{tabular}

F: female. M: male. ++: strong expression. +: moderate expression. -: negative or very weak expression.

In the context of CFSs, R-loops likely form due to replication being impeded by the presence of ongoing transcription at the locus. This would likely be particularly problematic in cases of a head-on collision between the replication and transcription machineries. In this context, it is clear that several CFSs have an unusual genomic structure that often incorporates a very long gene [39, 40]. Hence, transcription of the gene takes so long to complete (sometimes more than one entire cell cycle) that a collision between the transcription machinery and the replisome is inevitable at some point during S-phase. Considering that the FANCD2 protein is part of the socalled Fanconi anemia pathway, inactivation of which is responsible for a debilitating disorder associated with a predisposition to various cancers, its association with CFSs provides another line of evidence to suggest that the proper replication of CFSs is crucial for the suppression of oncogenesis. 

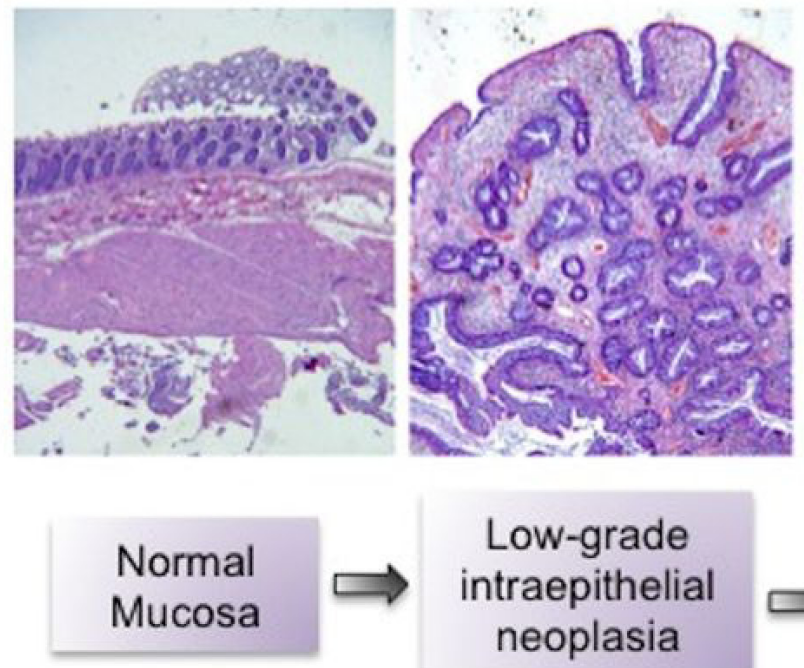$$
\text { Low-grade }
$$
neoplasia

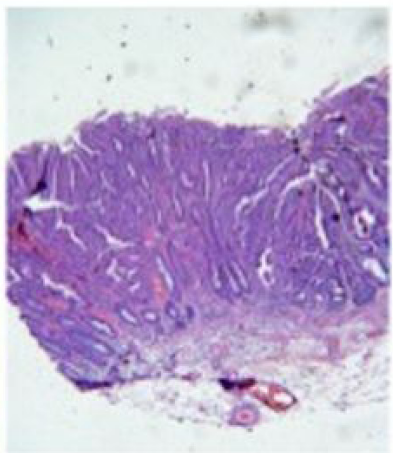

High-grade intraepithelial neoplasia

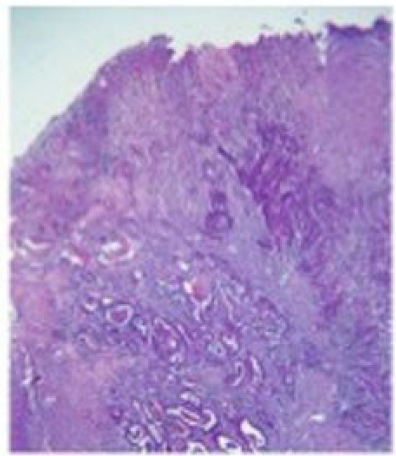

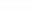
. DCC, SMAD4, $S M A D 2, K R A S$, AURKA TP53, PIGN, MEX3C, ZNF516, PIK3CA, AURKB, TERC

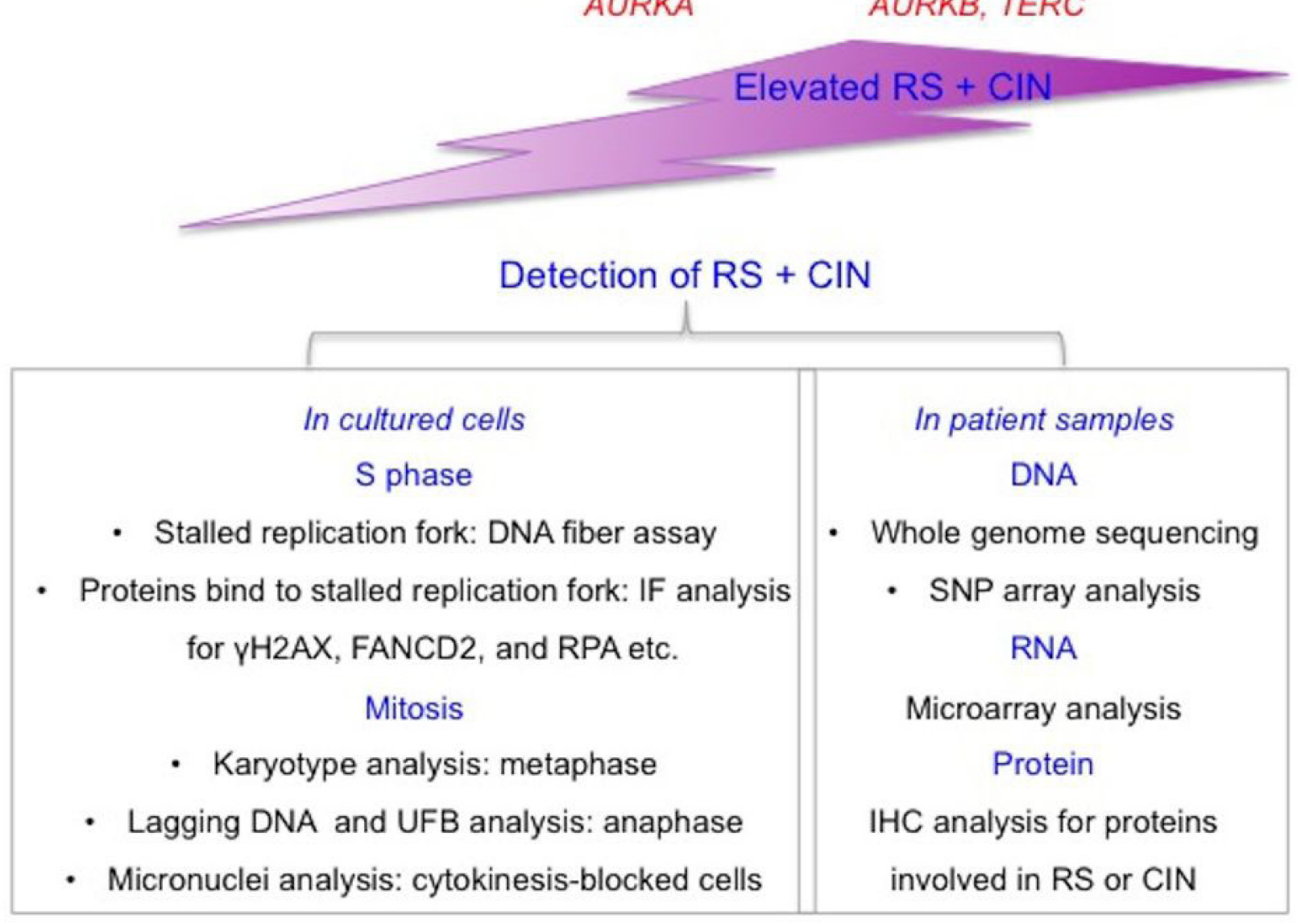

Figure 4: A summary of the underlying mechanisms and detection of RS and CIN in cancer samples. Top panel: An illustration of increasing levels of RS and CIN during multi-step carcinogenesis using colorectal cancer as an example. During this process, multiple tumor suppressor genes (in green below the diagram) lose their function in the maintenance of genome stability, while multiple oncogenes (in red below the diagram) become activated and stimulate cells to proliferate. The RS and CIN thus formed become mutually reinforcing events that allow the cancer cells to 'evolve' and develop metastatic potential and drug resistance. Lower panel: A summary of the methods that can be applied to the detection of RS and CIN in laboratory or clinic settings. RS: replication stress. CIN: chromosome instability. UFB: ultra-fine anaphase DNA bridge. IF: immunofluorescence. IHC: Immunohistochemistry. 
Table 2: Correlation analysis of the expression of Ki-67, Cyclin E, POLD3, $\gamma \mathrm{H} 2 \mathrm{AX}$, and FANCD2 in 32 FFPE specimens from colon, lung, breast, and stomach cancer patients.

\begin{tabular}{|l|c|c|c|c|c|}
\hline & Ki-67 & Cyclin E & POLD3 & $\gamma$ H2AX & FANCD2 \\
\hline Ki-67 & 1 & 0.34375 & 0.4375 & 0.5625 & 0.65625 \\
\hline Cyclin E & & 1 & $\mathbf{0 . 8 4 3 7 5}$ & 0.46875 & 0.5625 \\
\hline POLD3 & & & 1 & 0.4375 & 0.59375 \\
\hline $\boldsymbol{\gamma H 2 A X}$ & & & & 1 & 0.53125 \\
\hline FANCD2 & & & & & 1 \\
\hline
\end{tabular}

The expression scores for each protein in each sample were classified into two categories: strong/moderate expression (++, or + ) or absent/very weak expression (-). The two categories were then subjected to Jaccard similarity coefficient analysis for each protein. Jaccard index operates on a scale of $0-1$, with the higher the score denoting cases where the expression pattern between the two proteins examined is more similar. The Protein names are in bold and the highest Jaccard index number is highlighted in bold.

\section{Replication Stress in Cancer Cells}

In the past decade, evidence has emerged for a positive correlation between tumorigenesis and the degree of RS [41-44]. This suggests that RS is a plausible candidate for being a valuable biomarker in solid tumors. It is therefore essential to obtain detailed knowledge on the events and proteins involved in dealing with this form of stress in human cells. It is clear that, at the molecular level, the RS associated with oncogene activation in cancers can be generated in several ways, such as by atypical DNA secondary structures, including hairpins or G-quadruplexes, a specific chromatin structure that impedes replication fork progression or a collision between the replisome and the transcription machinery operating on the same template. Exogenous stress factors can also generate RS, including several classes of DNA damaging agents, as well as drugs that cause depletion or imbalance of dNTPs (reviewed in [45]). Furthermore, factors required for replication fork stability, repair and restart in response to RS, such as the BRCA1 and BRCA2 proteins, SLX4, and FA group members, have all been shown to associated with cancer development when their function is compromised in either human or mouse models (reviewed in [46]). This indicates that cancer cells have indeed developed various ways to cope with RS.

In normal cells, the ATR-CHK1 kinase cascade is employed to cope with RS (reviewed in [47]. However, the detailed mechanism underlying how stalled replication forks are repaired and DNA synthesis is re-initiated is still largely unknown. Several models, which are not mutually exclusive, have been proposed to explain this process. These include the re-priming of DNA synthesis at a nonorigin site, the activation of dormant origins to rescue sites of slow replication, template switching, and homologous recombination-based processes such as break-induced replication (BIR). In cancer cells, there is evidence to show that an abnormal DNA damage response is more likely to be associated with advanced cancer stage, and chemotherapy resistance although the results remains controversial due to the different tissue type and genetic background of the samples analyzed [48-51]. Moreover, there is evidence to indicate that some of the pathways that might permit cells to resist persistent RS are highly activated; for example, the error prone TLS pathway $[52,53]$. This suggests that the response to RS in cancer cells is deregulated in a more general way. This, in turn, could lead to CIN when cells containing under-replicated chromosomal regions (e.g. CFS regions) enter mitosis, because these regions have a tendency to missegregate in anaphase. Disturbances such as this in anaphase have the potential to drive chromosome nondisjunction or the formation of micronuclei in daughter cells. Interestingly, micronuclei are now recognized as a source of an extreme form of CIN called chromothripsis (a phenomenon by which multiple chromosomal rearrangements occur in a single event in localized genomic regions in one or a few chromosomes) that is increasingly being detected in cancer genomes.

Recently, we demonstrated that DNA synthesis can still be occurring at CFSs after the cell has entered mitosis, if the cells were treated with a low dose of APH in S phase [54]. We showed that entry into mitotic prophase triggers the recruitment of MUS81-EME1 to CFSs, and the nuclease activity of MUS81 then promotes a form of DNA synthesis that requires POLD3, a non-catalytic subunit of DNA Polymerase. POLD3 is the human ortholog of yeast Pol32, which plays a specialized role in certain forms of DNA repair in yeast, most notably BIR. Indeed, previous studies in human cells have proposed that POLD3 functions in a BIR-like pathway that is responsible for creating segmental genomic duplications [55]. It is most likely that the POLD3-dependent DNA synthesis present in mitosis (which we termed MiDAS; [56]) serves as a 'rescue' strategy in the cell to minimize chromosome missegregation and non-disjunction at CFSs in mitosis. Indeed, our data indicated that MiDAS play a particularly important role in the survival of cancer cells with CIN [54]. Very recently, we have demonstrated further that MiDAS often involves DNA synthesis taking place on a single sister chromatid, which is a hallmark of BIR [56].

Clearly, there is a need to define a set of markers that can indicate RS levels or the types of response to RS 
in cancer cells, which can be used for diagnosis, prognosis or for influencing therapeutic strategies for cancer. Despite the fact that inhibitors of the ATR and CHK1 kinases are undergoing clinical trials (reviewed in [57]), a biomarker for reliably indicating the level of RS is still not available for use in the clinic. The ideal biomarker assay for properly 'staging' a cancer patient should be sensitive, rapid, cost-effective, and robust against inter-operator and inter-institutional variability. In this regard, it has been proven very challenging to translate the information obtained from the laboratory to the 'bedside' (reviewed in [58]).

\section{A pilot study of possible markers on RS response}

Because RS is a common feature of most cancer cells, it is likely that RS exists in one form or another in a very wide range of cancer types. A corollary to this, therefore, is that the proteins involved in RS response pathways are strong candidates to be used as a biomarker of the degree of $\mathrm{RS}$, malignant potential or response to treatment in many cancer types. As a first step in testing this hypothesis, we carried out a pilot study to analyze the expression of five proteins (Ki-67, Cyclin E, POLD3, $\gamma \mathrm{H} 2 \mathrm{AX}$ and FANCD2) on a collection of 32 tumor samples from a representative range of cancer types (colon, lung, breast or stomach). These samples were chosen also because they represent a similar pathology grade (Table 1). The aim of this pilot study was to validate whether some of these markers are expressed in a consistent manner of tumors of similar histological grade regardless of their tissue origin or clinical stage. We optimized conditions for detection of the above proteins on paraffinembedded tissue sections using immunohistochemical (IHC) staining method, as most of these proteins have only been detected in cultured cells using immunofluorescence (Figure 2). Our results provide some expected and some very unexpected patterns of expression (Table 1). For example, the expression patterns of POLD3 and Cyclin E are strikingly similar in all of the samples (Table 2). These data correlate with the fact that POLD3 plays an important role in DNA replication and Cyclin E promotes S-phase entry. It might be expected, therefore, that the expression pattern of Cyclin E and POLD3 would correlate well with that of $\mathrm{Ki}-67$, an established proliferation marker used in pathology studies worldwide. However, they did not. Another curious finding was that the expression of $\gamma \mathrm{H} 2 \mathrm{AX}$ and FANCD2 rarely correlated with each other, despite the fact that in vitro studies using cell lines have indicated that $\gamma \mathrm{H} 2 \mathrm{AX}$ and FANCD2 activation are associated with RS, and commonly used as surrogate markers of RS arising at CFSs (Figure 3). Moreover, POLD3 plays a key role in counteracting RS at CFSs, and yet its expression did not correlate with either that of $\gamma \mathrm{H} 2 \mathrm{AX}$ or FANCD2. Overall, therefore, it is clear that the widely used RS markers in cell line studies need very careful evaluation in clinical biopsy samples before being considered serious contenders as useful biomarkers. Finally, it is worth noting that there was no obvious difference in the expression pattern of the proteins tested in the samples from different tumor types, which is consistent with the notion that RS is a common feature of a wide range of cancer types.

\section{DISCUSSION}

In recent years, there has been considerable progress in understanding the molecular events occurring during tumorigenesis. It is clear that abnormalities during DNA replication and the accompanying $\mathrm{RS}$ are common features of cancer cells. RS could be one of the most important drivers of genome instability, which in turn would permit cancer cells to develop phenotypic heterogeneity, such as an ability to metastasize or to acquire resistance to chemotherapy. Cancer cells have clearly evolved mechanisms to cope with persistent inherent RS. At the present time, we are in need a biomarker that can reliably detect RS in biopsies or reveal the cellular responses to RS that exist in cancers. Because of the routine use of cancer tissue pathology in clinics worldwide, it is important that these markers are robust enough to be studied using IHC based methods (Figure 4). Our pilot study indicates that it is possible to develop this kind of biomarker by testing various components in the RS pathways on both cancer cells in the laboratory and biopsies from cancer patients. Similar analysis should be performed in a larger collection of specimens with more comprehensive analysis relevant to the pathological and clinical characteristics of the tumors. Nevertheless, we hope this article, together with its pilot study, will facilitate future studies in this direction. The outcome of any biomarker analysis in the RS pathway would allow us to define whether the expression of proteins involved in the RS pathway could be a suitable predictor of the prognosis of patients treated with existing chemotherapy, or whether it could be used to stratify patients for treatment with one of the RS inhibitors that is being developed to target the RS pathway.

\section{MATERIALS AND METHODS}

\section{Cell lines and culture conditions}

Osteosarcoma cells (U2OS, obtained from ATCC) were maintained in Dulbecco's modified Eagle's medium (DMEM, Thermo Fisher Scientific) supplemented with $10 \%$ fetal bovine serum (FBS) and antibiotics. GM06865 lymphocytes (obtained from Coriell Biorepository) were maintained in RPMI 1640 medium (Thermo Fisher Scientific) supplemented with $15 \%$ FBS and antibiotics. Both types of cells were cultured at $37^{\circ} \mathrm{C}$ in an atmosphere of $5 \% \mathrm{CO} 2$. For replication stress analysis, asynchronously 
growing cells were seeded onto glass coverslips (SigmaAldrich) and were treated with $0.2 \mathrm{mM}$ hydroxyurea (HU; Sigma-Aldrich) for 16 hours. For karyotype analysis, asynchronously growing cells were treated with $0.1 \mu \mathrm{g} /$ $\mathrm{ml}$ colcemid (Karyomax, Thermo Fisher Scientific) for 5 hours before being harvested.

\section{Immunofluorescence (IF) analysis}

Cells fixed on glass cover slips were blocked with $3 \%$ BSA (Sigma-Aldrich) for 1 hour at room temperature and incubated with primary antibodies at $4^{\circ} \mathrm{C}$ overnight, followed by three washes (30 minutes each) using PBST (PBS with $0.2 \%$ Triton-X 100, Sigma-Aldrich). Slides were then incubated with secondary antibodies for 1 hour at room temperature, followed by three washes (30 minutes each) using PBST. Air-dried coverslips were mounted using Vectashield mounting medium with DAPI (Vector Laboratories), and were analyzed with a Retiga6000 camera connected to an Olympus BX63 microscope. The origins and dilutions of primary and secondary antibodies were: anti-FANCD2 (1:400, NB100182 ; Novus), anti- $\gamma \mathrm{H} 2 \mathrm{AX}$ (1:400, JBW-301; Millipore), Alexa Fluor 568 goat anti-rabbit IgG (1:500, A-1101; Invitrogen) and Alexa Fluor 488 goat anti-mouse IgG (1:500, A-110291; Invitrogen).

\section{Karyotype analysis}

The karyotype of metaphase cells was obtained by standard G-banding and analyzed using a Leica light microscope equipped with CytoVision software.

\section{Clinical specimens}

Archival blocks of formalin-fixed, paraffinembedded (FFPE) tumor, neoplasia or normal specimens from the colon $(n=13)$, lung $(n=8)$, breast $(n=9)$, or stomach $(n=5)$ were obtained in accordance with local Research Ethics guidelines. All of the specimens were chosen according to their histological classification and the degree of cell differentiation. Information concerning the tumor specimens chosen for immunohistochemical (IHC) staining is shown in Table 1.

\section{IHC staining and evaluation}

Sections $(5 \quad \mu \mathrm{m})$ were cut onto aminopropyltriethoxysilane (APES)-coated slides from each specimen. In each case, one of the sections was subjected to standard hematoxylin and eosin (H\&E) staining to confirm histological diagnosis, while the rest were subjected to IHC analysis using a SP9000, SPlink Detection Kit following manufacturer's instructions (Zhong Shan -Golden Bridge Biological Technology Co. Ltd., Beijing, China). The origins and the dilutions of the primary antibodies used are: antigamma H2AX (polyclonal, Abcam, ab2893, 1:400), anti-POLD3(monoclonal, Abcam, ab182564, 1:70), antiFANCD2 (monoclonal, Abcam, ab108928, 1:80), antiCyclinE (polyclonal, BIOSS, Bs-8929R, 1:150), and antiKi67 (monoclonal, Gene Tex, GTX83375, 1:400). All of the primary antibodies were incubated with pre-blocked slides at $4{ }^{\circ} \mathrm{C}$ overnight. The secondary antibodies were goat anti-mouse or goat anti-rabbit HRP for 30 minutes. 3,3'-diaminobenzidine (DAB) was used as the chromogen. Negative controls were preformed by omitting the primary antibody. The images were captured using an Olympus DP73 camera connected to an Olympus BX53 microscope. Staining results were assessed independently by three pathologists on coded samples.

The expression level of the protein analyzed was scored as described in [59]. In brief, the intensity of IHC staining was scored from 0 to 4 as: 0 , negative; 1 , weak; 2 , moderate; and 3, strong. The proportion of the cells stained positively was scored from 0 to 4 as: 0 , less than $5 \% ; 1,5-25 \% ; 2,26-50 \% ; 3,51-75$; and 4 , over $76 \%$. A final 'expression score' for each antibody in each specimen was achieved by multiplying the scores of intensity and proportion of the positive cells. Scores of 9-12 were defined as "strong expression", scores of 5-8 were defined as "reduced expression", and scores of 0-4 were defined as "negative or markedly reduced expression".

\section{Author contributions}

L.R., L.C., W.W., L.G., H.T., and Z.L. carried out experiments. I.V. performed data analysis. L.R., C.L., I.D.H. and Y.L. designed experiments and interpreted results. I.D.H. and Y.L. wrote the manuscript, and all authors edited it.

\section{ACKNOWLEDGMENTS}

We thank all members in Liu and Hickson groups for helpful discussions. We apologize to the authors whose work is not cited due to space restrictions.

\section{CONFLICTS OF INTEREST}

The authors have declared that no conflict of interest exists.

\section{FUNDING}

The work in the authors' laboratory is supported by The Department Of Science And Technology of Hebei province, China (169A76220H) (L.R.), Chinese Scholarship Council (W.W.), European Union (I.D.H., and 
Y.L.), The Danish National Research Foundation (I.D.H. and Y.L.), and The Nordea Foundation (I.D.H.).

\section{REFERENCES}

1. WHO. Cancer fact sheets: All cancers excluding nonmelanoma skin. http://gco.iarc.fr/today/fact-sheetscancers? cancer $=29 \&$ type $=0 \& \operatorname{sex}=0,2013$.

2. NIH. Cancer Stat Facts: Colon and Rectum Cancer. https:// seer.cancer.gov/statfacts/html/colorect.html, 2016.

3. Wood LD, Parsons DW, Jones S, Lin J, Sjoblom T, Leary RJ, Shen D, Boca SM, Barber T, Ptak J, Silliman N, Szabo $\mathrm{S}$, Dezso Z, et al. The genomic landscapes of human breast and colorectal cancers. Science. 2007; 318:1108-1113.

4. Lecona E, Fernandez-Capetillo O. Replication stress and cancer: it takes two to tango. Exp Cell Res. 2014; 329:2634.

5. Hills SA, Diffley JF. DNA replication and oncogeneinduced replicative stress. Curr Biol. 2014; 24:R435-444.

6. Sansregret L, Swanton C. The Role of Aneuploidy in Cancer Evolution. Cold Spring Harb Perspect Med. 2017; 7.

7. Burrell RA, McClelland SE, Endesfelder D, Groth P, Weller MC, Shaikh N, Domingo E, Kanu N, Dewhurst SM, Gronroos E, Chew SK, Rowan AJ, Schenk A, et al. Replication stress links structural and numerical cancer chromosomal instability. Nature. 2013; 494:492-496.

8. Harris H. Concerning the origin of malignant tumours by Theodor Boveri. Translated and annotated by Henry Harris. J Cell Sci. 2008; 121: v-vi.

9. Rajagopalan H, Lengauer C. Aneuploidy and cancer. Nature. 2004; 432:338-341.

10. Hanks S, Coleman K, Reid S, Plaja A, Firth H, Fitzpatrick D, Kidd A, Mehes K, Nash R, Robin N, Shannon N, Tolmie J, Swansbury J, et al. Constitutional aneuploidy and cancer predisposition caused by biallelic mutations in BUB1B. Nat Genet. 2004; 36:1159-1161.

11. Hernando E, Nahle Z, Juan G, Diaz-Rodriguez E, Alaminos M, Hemann M, Michel L, Mittal V, Gerald W, Benezra R, Lowe SW, Cordon-Cardo $\mathrm{C}$. Rb inactivation promotes genomic instability by uncoupling cell cycle progression from mitotic control. Nature. 2004; 430:797-802.

12. Putkey FR, Cramer T, Morphew MK, Silk AD, Johnson RS, McIntosh JR, Cleveland DW. Unstable kinetochoremicrotubule capture and chromosomal instability following deletion of CENP-E. Dev Cell. 2002; 3:351-365.

13. Cimini D, Cameron LA, Salmon ED. Anaphase spindle mechanics prevent mis-segregation of merotelically oriented chromosomes. Curr Biol. 2004; 14:2149-2155.

14. Cimini D, Moree B, Canman JC, Salmon ED. Merotelic kinetochore orientation occurs frequently during early mitosis in mammalian tissue cells and error correction is achieved by two different mechanisms. J Cell Sci. 2003; 116:4213-4225.

15. Godek KM, Kabeche L, Compton DA. Regulation of kinetochore-microtubule attachments through homeostatic control during mitosis. Nat Rev Mol Cell Biol. 2015; 16:5764.

16. Nigg EA, Stearns T. The centrosome cycle: Centriole biogenesis, duplication and inherent asymmetries. Nature cell biology. 2011; 13:1154-1160.

17. Solomon DA, Kim T, Diaz-Martinez LA, Fair J, Elkahloun AG, Harris BT, Toretsky JA, Rosenberg SA, Shukla N, Ladanyi M, Samuels Y, James CD, Yu H, et al. Mutational inactivation of STAG2 causes aneuploidy in human cancer. Science. 2011; 333:1039-1043.

18. Tanno Y, Susumu H, Kawamura M, Sugimura H, Honda $\mathrm{T}$, Watanabe $\mathrm{Y}$. The inner centromere-shugoshin network prevents chromosomal instability. Science. 2015; 349:12371240.

19. Richards RI. Fragile and unstable chromosomes in cancer: causes and consequences. Trends in genetics. 2001; 17:339345 .

20. Arlt MF, Durkin SG, Ragland RL, Glover TW. Common fragile sites as targets for chromosome rearrangements. DNA Repair. 2006; 5:1126-1135.

21. Balci A, Ekmekc A, Cetin R. The expression of common fragile sites in peripheral blood lymphocytes of breast and colorectal cancer patients with aphidicolin. Tohoku J Exp Med. 1999; 189:107-116.

22. Bouffler S, Silver A, Papworth D, Coates J, Cox R. Murine Radiation Myeloid Leukemogenesis - Relationship between Interstitial Telomere-Like Sequences and Chromosome-2 Fragile Sites. Gene Chromosome Canc. 1993; 6:98-106.

23. Finnon R, Moody J, Meijne E, Haines J, Clark D, Edwards A, Cox R, Silver A. A major breakpoint cluster domain in murine radiation-induced acute myeloid leukemia. Mol Carcinogen. 2002; 34:64-71.

24. Gumus G, Sunguroglu A, Tukun A, Sayin DB, Bokesoy I. Common fragile sites associated with the breakpoints of chromosomal aberrations in hematologic neoplasms. Cancer Genet Cytogen. 2002; 133:168-171.

25. Savelyeva L, Brueckner LM. Molecular characterization of common fragile sites as a strategy to discover cancer susceptibility genes. Cell Mol Life Sci. 2014; 71:45614575 .

26. Helmrich A, Stout-Weider K, Hermann K, Schrock E, Heiden T. Common fragile sites are conserved features of human and mouse chromosomes and relate to large active genes. Genome Res. 2006; 16:1222-1230.

27. Durkin SG, Glover TW. Chromosome fragile sites. Annual review of genetics. 2007; 41:169-192.

28. Mrasek K, Schoder C, Teichmann AC, Behr K, Franze B, Wilhelm K, Blaurock N, Claussen U, Liehr T, Weise A. Global screening and extended nomenclature for 230 aphidicolin-inducible fragile sites, including 61 yet unreported ones. International journal of oncology. 2010; 36:929-940.

29. Sutherland GR. Rare fragile sites. Cytogenetic and genome 
research. 2003; 100:77-84.

30. El Achkar E, Gerbault-Seureau M, Muleris M, Dutrillaux B, Debatisse M. Premature condensation induces breaks at the interface of early and late replicating chromosome bands bearing common fragile sites. Proc Natl Acad Sci U S A. 2005; 102:18069-18074.

31. Casper AM, Nghiem P, Arlt MF, Glover TW. ATR regulates fragile site stability. Cell. 2002; 111:779-789.

32. Arlt MF, Xu B, Durkin SG, Casper AM, Kastan MB, Glover TW. BRCA1 is required for common-fragile-site stability via its $\mathrm{G} 2 / \mathrm{M}$ checkpoint function. Mol Cell Biol. 2004; 24:6701-6709.

33. Durkin SG, Arlt MF, Howlett NG, Glover TW. Depletion of CHK1, but not CHK2, induces chromosomal instability and breaks at common fragile sites. Oncogene. 2006; 25:43814388.

34. Howlett NG, Taniguchi T, Durkin SG, D’Andrea AD, Glover TW. The Fanconi anemia pathway is required for the DNA replication stress response and for the regulation of common fragile site stability. Human molecular genetics. 2005; 14:693-701.

35. Schwartz M, Zlotorynski E, Goldberg M, Ozeri E, Rahat A, le Sage C, Chen BPC, Chen DJ, Agami R, Kerem B. Homologous recombination and nonhomologous endjoining repair pathways regulate fragile site stability. Genes \& development. 2005; 19:2715-2726.

36. Chan KL, Palmai-Pallag T, Ying SM, Hickson ID. Replication stress induces sister-chromatid bridging at fragile site loci in mitosis. Nature cell biology. 2009; 11:753-U120.

37. Ying SM, Minocherhomji S, Chan KL, Palmai-Pallag T, Chu WK, Wass T, Mankouri HW, Liu Y, Hickson ID. MUS81 promotes common fragile site expression. Nature cell biology. 2013; 15:1001-1007.

38. Madireddy A, Kosiyatrakul ST, Boisvert RA, HerreraMoyano E, Garcia-Rubio ML, Gerhardt J, Vuono EA, Owen N, Yan Z, Olson S, Aguilera A, Howlett NG, Schildkraut CL. FANCD2 Facilitates Replication through Common Fragile Sites. Molecular cell. 2016; 64:388-404.

39. Le Tallec B, Millot GA, Blin ME, Brison O, Dutrillaux B, Debatisse M. Common Fragile Site Profiling in Epithelial and Erythroid Cells Reveals that Most Recurrent Cancer Deletions Lie in Fragile Sites Hosting Large Genes. Cell Rep. 2013; 4:420-428.

40. Wilson TE, Arlt MF, Park SH, Rajendran S, Paulsen M, Ljungman M, Glover TW. Large transcription units unify copy number variants and common fragile sites arising under replication stress. Genome Res. 2015; 25:189-200.

41. Barlow JH, Faryabi RB, Callen E, Wong N, Malhowski A, Chen HT, Gutierrez-Cruz G, Sun HW, McKinnon P, Wright G, Casellas R, Robbiani DF, Staudt L, et al. Identification of early replicating fragile sites that contribute to genome instability. Cell. 2013; 152:620-632.

42. Blumrich A, Zapatka M, Brueckner LM, Zheglo D, Schwab
M, Savelyeva L. The FRA2C common fragile site maps to the borders of MYCN amplicons in neuroblastoma and is associated with gross chromosomal rearrangements in different cancers. Human molecular genetics. 2011; 20:1488-1501.

43. Pelliccia F, Bosco N, Rocchi A. Breakages at common fragile sites set boundaries of amplified regions in two leukemia cell lines K562 - Molecular characterization of FRA2H and localization of a new CFS FRA2S. Cancer Lett. 2010; 299:37-44.

44. Tomasetti C, Vogelstein B. Cancer etiology. Variation in cancer risk among tissues can be explained by the number of stem cell divisions. Science. 2015; 347:78-81.

45. Munoz S, Mendez J. DNA replication stress: from molecular mechanisms to human disease. Chromosoma. 2016; 126:1-15.

46. Gaillard H, Garcia-Muse T, Aguilera A. Replication stress and cancer. Nat Rev Cancer. 2015; 15:276-289.

47. Cimprich KA, Cortez D. ATR: an essential regulator of genome integrity. Nat Rev Mol Cell Biol. 2008; 9:616-627.

48. Bi J, Huang A, Liu T, Zhang T, Ma H. Expression of DNA damage checkpoint 53BP1 is correlated with prognosis, cell proliferation and apoptosis in colorectal cancer. Int J Clin Exp Pathol. 2015; 8:6070-6082.

49. Neboori HJ, Haffty BG, Wu H, Yang Q, Aly A, Goyal S, Schiff D, Moran MS, Golhar R, Chen C, Moore D, Ganesan S. Low p53 binding protein 1 (53BP1) expression is associated with increased local recurrence in breast cancer patients treated with breast-conserving surgery and radiotherapy. Int J Radiat Oncol Biol Phys. 2012; 83:e677683.

50. Pennington KP, Wickramanayake A, Norquist BM, Pennil CC, Garcia RL, Agnew KJ, Taniguchi T, Welcsh P, Swisher EM. 53BP1 expression in sporadic and inherited ovarian carcinoma: Relationship to genetic status and clinical outcomes. Gynecol Oncol. 2013; 128:493-499.

51. Takeyama K, Monti S, Manis JP, Dal Cin P, Getz G, Beroukhim R, Dutt S, Aster JC, Alt FW, Golub TR, Shipp MA. Integrative analysis reveals 53BP1 copy loss and decreased expression in a subset of human diffuse large B-cell lymphomas. Oncogene. 2008; 27:318-322.

52. Albertella MR, Lau A, O'Connor MJ. The overexpression of specialized DNA polymerases in cancer. DNA Repair (Amst). 2005; 4:583-593.

53. Shi TY, Yang L, Yang G, Tu XY, Wu X, Cheng X, Wei Q. DNA polymerase zeta as a potential biomarker of chemoradiation resistance and poor prognosis for cervical cancer. Med Oncol. 2013; 30:500.

54. Minocherhomji S, Ying S, Bjerregaard VA, Bursomanno $\mathrm{S}$, Aleliunaite A, Wu W, Mankouri HW, Shen H, Liu Y, Hickson ID. Replication stress activates DNA repair synthesis in mitosis. Nature. 2015; 528:286-290.

55. Costantino L, Sotiriou SK, Rantala JK, Magin S, Mladenov E, Helleday T, Haber JE, Iliakis G, Kallioniemi OP, 
Halazonetis TD. Break-induced replication repair of damaged forks induces genomic duplications in human cells. Science. 2014; 343:88-91.

56. Bhowmick R, Minocherhomji S, Hickson ID. RAD52 Facilitates Mitotic DNA Synthesis Following Replication Stress. Molecular cell. 2016; 64:1117-1126.

57. Dobbelstein M, Sorensen CS. Exploiting replicative stress to treat cancer. Nat Rev Drug Discov. 2015; 14:405-423.
58. Ludwig JA, Weinstein JN. Biomarkers in cancer staging, prognosis and treatment selection. Nat Rev Cancer. 2005; 5:845-856.

59. Hao XP, Pretlow TG, Rao JS, Pretlow TP. Beta-catenin expression is altered in human colonic aberrant crypt foci. Cancer Res. 2001; 61:8085-8088. 